\title{
Clinical Features, Renal recovery and Predictors of Acute Kidney Injury in a Resource-Limited Country: A Prospective Study
}

\author{
Abinet Abebe ( $\nabla$ abinetabebe.21@gmail.com ) \\ Mizan-Tepi University \\ Kabaye Kumela \\ Jimma University \\ Maekel Belay \\ Jimma University \\ Abdela Birhan \\ Ambo University \\ Yohannes Wobie \\ Mizan-Tepi University \\ Erkihun Assefa \\ Mizan-Tepi University
}

\section{Research Article}

Keywords: Acute kidney injury, renal recovery, predictors, Ethiopia

Posted Date: February 2nd, 2022

DOI: https://doi.org/10.21203/rs.3.rs-1315964/v1

License: (c) (i) This work is licensed under a Creative Commons Attribution 4.0 International License. Read Full License 


\section{Abstract \\ Background}

Recovery from acute kidney injury (AKI) in hospitalized patients is variable and persistent impairment of renal function at discharge is associated with long-term adverse outcomes. Understanding the risk factors for non-recovery AKI may help to avoid modifiable determinants and enhance recovery. However, data on renal recovery and its associated factors is limited, especially in resource-limited settings. This study aimed to assess the clinical features, renal recovery, and predictors of AKI among hospitalized patients in Ethiopia.

\section{Methods}

A prospective observational study was conducted involving all adult patients with age $\geq 18$ years, and met the kidney disease: improving global outcomes criteria for AKI from April to July 2019. The main outcome variable was renal recovery at discharge. The logistic regression model was used to determine predictors of non-recovery from AKI. Statistical significance was considered at a p-value of less than 0.05 on multivariate analysis.

\section{Results}

Of the 169 patients included in the study over four months, $127(75.2 \%)$ were $<60$ years, $121(71.6 \%)$ had kidney disease on admission, almost one-third (33.1\%) of them had stage $3 \mathrm{AKI}$, nearly half $(50.29 \%)$ had prerenal AKI, and 32(19\%) had exposure to nephrotoxins. Vomiting 31(18.34\%), oliguria $42(24 \%)$, hematuria $15(25.4 \%)$, and proteinuria $26(40.6 \%)$ were common presenting features. Of the total study participants, most of them (68\%) had complete renal recovery and fifty-four (32\%) patients had non-recovery AKI at the time of hospital discharge. On multivariable analysis, proteinuria (AOR 6.2, Cl 1.25-31.4, $p=0.002$ ), AKI stage III (AOR 4.7, $\mathrm{Cl} 1.37-28.6, p=0.019)$, and nephrotoxin exposure (AOR 5.2, $\mathrm{Cl} 2.1-14.89, \mathrm{p}=0.007$ ) were factors significantly associated with non-renal recovery.

\section{Conclusions}

Our study found that most of the patients had AKI on admission and one-third had a higher stage of AKI. A higher proportion of patients were found to have non-recovery AKI at hospital discharge. Renal non-recovery was significantly associated with the severity of AKI, nephrotoxic drug use, and proteinuria. Follow-up of serum creatinine and proteinuria, and careful drug use monitoring may help to identify patients with poor prognosis, initiate specific interventions, and improve renal recovery.

\section{Introduction}

Acute kidney injury (AKI) is a major complication of hospitalized patients and a predictor of poor short-and long-term outcomes. It occurred in over 1 of 5 adult hospitalizations, with pooled worldwide incidence rates 
of $21.6 \%(1,2,3)$. About 13.3 million people are shown to develop AKI per year, $85 \%$ of them live in resourcelimited countries (4).

Acute kidney injury is associated with a higher in-hospital to 6-month mortality, with a mortality rate ranging from $20-60 \%(5,6)$. Moreover, the condition is associated with other adverse short-and long-term renal and non-renal outcomes including systemic complications, recurrent disease, progression to chronic kidney disease (CKD), end-stage renal disease (ESRD), cardiovascular events, length of hospital stay, hospital readmission, and cost to health care. Regardless of its severity, AKI is associated with a greater risk of morbidity and mortality $(7,8,9,10,11)$.

The degree of recovery from subsequent episodes of AKI is shown to substantially affect these poor shortand long-term outcomes. Furthermore, age, hypertension, diabetes, preexisting CKD, and proteinuria are some of the factors found to be associated with a low rate of renal recovery. Recovery from AKI is a potentially modifiable event and measures taken to prevent the modifiable determinants can increase the probability of renal recovery $(12,13)$.

Understanding the risk factors for non-recovery after AKI may help for early initiation of specific interventions to enhance recovery, determine the duration of follow-up, and improve outcomes of AKI (13). However, despite persistent $\mathrm{AKI}$ at discharge has been known to be associated with poor long-term outcomes, data on renal recovery in surviving patients is sparse, especially in resource-limited countries. Therefore, this study aimed to assess the clinical features, renal recovery, and predictors of acute kidney injury among hospitalized patients admitted to a teaching hospital in Ethiopia.

\section{Material And Methods}

\section{Study setting and period}

This study was done parallel with other studies (14) from April 1 to July 30, 2019, at the medical ward of Jimma medical center, Southwest Ethiopia. Jimma medical center is the only teaching and referral hospital in the southwestern part of Ethiopia with an 800-bed capacity. Currently, it provides services for approximately 15,000 inpatient, 160,000 outpatient attendants, with a catchment population of around 15 million people. The internal medicine department of the hospital has two renal units and provides nephrologist-guided care to the patients.

\section{Study design and Population}

A four-month prospective observational study was conducted. All adult patients with age $\geq 18$ years, and who met the kidney disease: Improving Global Outcomes (KDIGO) criteria for AKI were recruited consecutively. All patients who gave written informed consent were included in the study. Patients with underlying CKD, unable to give the required information, hospitalized for less than 48 hours, died, selfdischarged, and referred to other institutions were excluded from the study.

\section{Definition of AKI and outcomes}


Definition of AKI and its severity was according to the KDIGO 2012 AKI criteria (1). Community-acquired AKI is AKI that is detected at admission, or within 48 hours of hospital admission. We used the serum creatinine obtained within seven days to three months of hospital admission, if unavailable, or the minimum and or most recent value of serum creatinine at the time of hospital admission was used as the baseline for community-acquired $\operatorname{AKI}(15,16,17)$. For patients with hospital-acquired $\mathrm{AKI}$, the first documented serum creatinine on admission was used as the baseline(1). The discharge creatinine was the last creatinine measured as an inpatient. The duration of anuria was defined as the time in which urine output was less than $0.5 \mathrm{~mL} / \mathrm{kg} / \mathrm{hr}$

The main outcome variable was renal recovery at hospital discharge. Recovery was defined as reversal at discharge or return to baseline kidney function. Reversal from the AKI episode was defined as no longer meeting AKI criteria. The pattern of renal recovery was defined as (I) early sustained reversal: recovery from AKI within two days, (II) late sustained reversal: recovery after two days and sustained through hospital discharge, (III) relapsing AKI with complete recovery, (IV) relapsing AKI without complete recovery, and (V) never recovery $(18,19,20,21)$. The first three were considered as complete recovery and the last two as nonrecovery $\mathrm{AKI}$, defined as $\mathrm{AKI}$ not returned to baseline kidney function at discharge.

\section{Data collection and statistical analysis}

Data was collected by trained health professionals using a data abstraction checklist. Clinical and demographic characteristics including age, gender, clinical presentations, diagnosis, underlying comorbidities, laboratory results, and medications were collected from the patient's medical records prospectively. Serum creatinine and urine output results were reviewed daily until the patient's discharge from the hospital. Data was entered to Epi data version 4.4.2 and exported to SPSS version 26.0 for analysis. The data were presented as mean $\pm(\mathrm{SD})$ and median(IQR, interquartile range) for continuous variables and frequency and proportions for categorical variables. The Chi-square test was used for the comparison of the proportions of categorical variables. The logistic regression model was used to determine predictors of nonrecovery AKI at hospital discharge. Variables with a $\mathrm{P}$ value of less than 0.25 from the univariate analysis were included for multivariate analysis. Statistical significance was considered at a p-value of less than 0.05 on multivariate analysis.

\section{Results}

\section{Baseline clinical characteristics of patients}

The study included $169 \mathrm{AKI}$ patients admitted to the internal medicine ward during the study period and fulfill the inclusion criteria. The mean $( \pm S D)$ age was $49.91 \pm 15.17$ (range 18-80) years and the majority of the patients (58.6\%) were men. Of the patients, most of them (71.6\%) had AKI on admission and almost onethird (33.1\%) had KIDGO stage $3 \mathrm{AKI}$. The commonest clinical presentations among the study participants were vomiting $31(18.34 \%)$, anuria $11(6.5 \%)$, oliguria $42(24 \%)$, hematuria $15(25.4 \%)$, and proteinuria $26(40.6 \%)$. Concerning the cause of AKI, more than half of them (53\%) had prerenal AKI, $28(17 \%)$ had intrinsic AKI, and 15(9\%) had postrenal AKI. Hypertension (44.4\%), heart failure (44.4\%), and anemia (7.1\%) were common underlying comorbidities identified. Of the patients, 32(19\%) patients had exposure to 
nephrotoxins, among these, non-steroidal anti-inflammatory drugs (NSAIDs) and Angiotensin-converting enzyme inhibitors (ACEls) comprise the higher frequency with 17(10\%), and 9(5.3\%), respectively. Vancomycin $4(2.4 \%)$ and gentamycin $2(1.2 \%)$ were the other nephrotoxins prescribed in AKI patients (Table 1).

\section{Laboratory values of patients}

Urinalysis was done for 64 patients. Of this, $26(40.6 \%)$ had proteinuria and $15(25.4 \%)$ had hematuria. On the other hand, urine output was assessed for $103(60.94 \%)$ patients, $11(10.7 \%)$ had anuria and $42(40.8 \%)$ had oliguria. Close to two-thirds (66.3\%) of the patients had serum electrolyte assessment. Of this, $28(25 \%)$ had hyperkalemia, 32(28.6\%) had hyponatremia, and 15(13.4\%) had Hypocalcemia (Table 2).

Table 1: Baseline clinical characteristics of AKI patients by renal recovery 


\begin{tabular}{|c|c|c|c|c|}
\hline Variables & Category & Total n (\%) & Recovery (115) & Non-recovery (54) \\
\hline \multirow[t]{2}{*}{ Age } & $<60$ & $127(75.2 \%)$ & $92(54.4 \%)$ & $35(20.8 \%)$ \\
\hline & $\geq 60$ & $42(24.8 \%)$ & $23(13.6 \%)$ & 19(11.2\%) \\
\hline \multirow[t]{2}{*}{ Sex } & Male & $99(58.6 \%)$ & $66(39 \%)$ & $33(19.5 \%)$ \\
\hline & Female & $70(41.4 \%)$ & $49(29 \%)$ & $21(12.5 \%)$ \\
\hline \multirow[t]{3}{*}{ Stage of AKI } & Stage 1 & $73(43.2 \%)$ & $61(36.1 \%)$ & $12(7.1 \%)$ \\
\hline & Stage 2 & $40(23.7 \%)$ & $29(17.2 \%)$ & $11(6.5 \%)$ \\
\hline & Stage 3 & $56(33.1 \%)$ & $25(14.8 \%)$ & $31(18.3 \%)$ \\
\hline \multirow[t]{2}{*}{ Hypertension } & Yes & $75(44.4 \%)$ & $42(24.8 \%)$ & $33(19.6 \%)$ \\
\hline & No & $94(55.6 \%)$ & $73(43.2 \%)$ & $21(12.4 \%)$ \\
\hline \multirow[t]{2}{*}{ Diabetes } & Yes & $6(3.6 \%)$ & $2(1.2 \%)$ & $4(2.4 \%)$ \\
\hline & No & $163(96.4 \%)$ & $113(66.8 \%)$ & $50(29.6 \%)$ \\
\hline \multirow[t]{2}{*}{ Heart failure } & Yes & $75(44.4 \%)$ & $44(26 \%)$ & $31(18.4 \%)$ \\
\hline & No & $94(55.6 \%)$ & $71(42 \%)$ & $23(13.6 \%)$ \\
\hline \multirow[t]{2}{*}{ Anemia } & Yes & $12(7.1 \%)$ & $10(5.9 \%)$ & $2(1.2 \%)$ \\
\hline & No & $157(92.9 \%)$ & $105(62.1 \%)$ & $52(30.8 \%)$ \\
\hline \multirow[t]{2}{*}{ Nephrotoxins } & Yes & $32(19 \%)$ & $15(9 \%)$ & $17(10 \%)$ \\
\hline & No & $137(81 \%)$ & $100(59 \%)$ & $37(22 \%)$ \\
\hline \multirow{2}{*}{$\begin{array}{c}\text { Serum } \\
\text { potassium }\end{array}$} & Hyperkalemia & $28(25 \%)$ & $10(8.9 \%)$ & $18(16.1 \%)$ \\
\hline & Hypokalemia & $11(9.8 \%)$ & $7(6.3 \%)$ & $4(3.5 \%)$ \\
\hline Serum sodium & Hyponatremia & $32(28.6 \%)$ & $19(17 \%)$ & $13(11.6 \%)$ \\
\hline Serum calcium & Hypocalcemia & $15(13.4 \%)$ & $9(8 \%)$ & $6(5.4 \%)$ \\
\hline Chloride & Hyperchloremia & $11(9.8 \%)$ & $5(4.5 \%)$ & $6(5.3 \%)$ \\
\hline \multirow[t]{2}{*}{ Urine output } & Anuria & $11(10.7 \%)$ & $4(3.9 \%)$ & $7(6.8 \%)$ \\
\hline & Oliguria & $42(40.8 \%)$ & $27(26.21 \%)$ & $15(14.56 \%)$ \\
\hline \multirow[t]{2}{*}{ Urinalysis } & Proteinuria & $26(40.6 \%)$ & $14(21.8 \%)$ & $12(18.8 \%)$ \\
\hline & Hematuria & $15(25.4 \%)$ & $4(6.8 \%)$ & 11(18.6\%) \\
\hline
\end{tabular}

Abbreviations: AKI, acute kidney injury,

Table 2: Laboratory values of AKI patients by renal recovery 


\begin{tabular}{|c|c|c|c|}
\hline Variables & Category & Recovery & Non-recovery \\
\hline Baseline Scr & $\begin{array}{l}\text { Mean } \pm \text { SD (min, } \\
\text { max) }\end{array}$ & $\begin{array}{ll}1.14 \pm 0.40 \\
2.44)\end{array}$ & $\begin{array}{lll}2.47 \pm & 1.02 & (0.70 \\
4.76) & & \\
\end{array}$ \\
\hline Admission Scr & $\begin{array}{l}\text { Mean } \pm \text { SD (min, } \\
\text { max) }\end{array}$ & $\begin{array}{l}4.45 \pm 3.07(2.21 \\
13.80)\end{array}$ & $\begin{array}{l}7.25 \pm 4.95 \\
20.10)\end{array}$ \\
\hline Discharge Scr & $\begin{array}{l}\text { Mean } \pm \text { SD (min, } \\
\text { max) }\end{array}$ & $\begin{array}{l}3.22 \pm \\
5.52)\end{array} \quad$ 2.61(0.91, & $5.84 \pm 3.85(1.6,15.10)$ \\
\hline Admission BUN & $\begin{array}{l}\text { Mean } \pm \text { SD (min, } \\
\text { max) }\end{array}$ & $\begin{array}{l}96.21 \pm 74.36 \\
375)\end{array}$ & $\begin{array}{l}123.29 \pm 85.53(40, \\
375)\end{array}$ \\
\hline Discharge BUN & $\begin{array}{l}\text { Mean } \pm \text { SD (min, } \\
\text { max) }\end{array}$ & $\begin{array}{l}86.07 \pm 70.05(17.25, \\
525)\end{array}$ & $\begin{array}{ll}93.30 \pm 80.23 & (32.10, \\
465) & \\
\end{array}$ \\
\hline Serum sodium & $\begin{array}{l}\text { Mean } \pm \text { SD (min, } \\
\text { max) }\end{array}$ & $\begin{array}{l}135.02 \pm \\
3.3(128,141) \\
\end{array}$ & $\begin{array}{l}133.17 \pm 9.37(119, \\
144)\end{array}$ \\
\hline Serum potassium & $\begin{array}{l}\text { Mean } \pm \text { SD } \quad(\min , \\
\max )\end{array}$ & $4.32 \pm 1.91(1.89,6.5)$ & $4.80 \pm 2.45(2.50,7.10)$ \\
\hline Calcium (ionized) & $\begin{array}{l}\text { Mean } \pm \text { SD (min, } \\
\text { max) }\end{array}$ & $1.06 \pm 0.16(0.67,1.33)$ & $\begin{array}{l}1.05 \pm 0.26 \quad(0.60, \\
1.28)\end{array}$ \\
\hline Chloride & $\begin{array}{l}\text { Mean } \pm \text { SD (min, } \\
\text { max) }\end{array}$ & $\begin{array}{l}107.76 \pm \\
10.61(94,138)\end{array}$ & $\begin{array}{l}111.55 \pm 9.95 \quad(106 \\
140)\end{array}$ \\
\hline $\begin{array}{lll}\begin{array}{l}\text { Duration of } \\
\text { (days) }\end{array} & & \\
\end{array}$ & $\begin{array}{l}\text { Mean } \pm \text { SD (min, } \\
\text { max) }\end{array}$ & $2.81 \pm 0.72(2,6)$ & $4.26 \pm 1.71(3,11)$ \\
\hline $\begin{array}{l}\begin{array}{l}\text { Duration of oliguria } \\
\text { (days) }\end{array} \\
\end{array}$ & $\begin{array}{l}\text { Mean } \pm \text { SD (min, } \\
\text { max) }\end{array}$ & $1.94 \pm 0.89(1,5)$ & $2.44 \pm 1.10(2,4)$ \\
\hline Hemoglobin & $\begin{array}{l}\text { Mean } \pm \text { SD (min, } \\
\text { max) }\end{array}$ & $\pm 3.1(6.01$ & $10.01 \pm 3.2(5.5,14.2)$ \\
\hline WBC & $\begin{array}{l}\text { Mean } \pm \text { SD (min, } \\
\text { max) }\end{array}$ & $9.7 \pm 5.4(3.6,18.00)$ & $8.95 \pm 3.40(4.5,16.0)$ \\
\hline $\mathrm{RBC}$ & $\begin{array}{l}\text { Mean } \pm \text { SD (min, } \\
\text { max) }\end{array}$ & $3.69 \pm 1.03(2.55,5.80)$ & $3.68 \pm 1.05(2.01,5.32)$ \\
\hline Platelet & $\begin{array}{l}\text { Mean } \pm \text { SD (min, } \\
\max )\end{array}$ & $\begin{array}{l}261.6 \pm \\
98.40(126,462)\end{array}$ & $\begin{array}{l}241.2 \pm 103.3 \\
369)\end{array}$ \\
\hline
\end{tabular}

Abbreviations: Scr; Serum creatinine, BUN; Blood urea nitrogen, Min; Minimum, Max; Maximum

\section{Outcomes: Patterns of renal recovery}

Among the study participants, more than two-thirds (68\%) of the patients had complete renal recovery at hospital discharge. From this, $17(10 \%)$ had early sustained reversal, $78(46 \%)$ had a late sustained reversal, the other 20(12\%) had relapsing AKI with complete recovery at discharge. Recovery was more likely in stage $1(36.1 \%)$ and stage $2(17.2 \%)$ than in stage $3 \mathrm{AKI}(14.8 \%)$. In addition, the median time from AKI diagnosis to complete renal recovery was increased with the stage of AKI. Patients with stage I had 3 days (IQR 2-7) while patients with stage II had 7 days (IQR 4-11), and patients with stage III had 12 days (IQR 10-22). Fiftyfour (32\%) patients had non-recovery AKI at discharge. From this, 23 (13.6\%) patients had relapsing AKI 
without recovery and $31(18.4 \%)$ patients never recovered during their hospital stay. The rate of non-recovery was proportional to the severity of AKI, as a higher rate of non-recovery was observed in stage $3 \mathrm{AKI}(18.3 \%)$ than in stage II (6.5\%), and stage I (7.1\%) AKI (Figure 1). Moreover, a higher mean ( \pm SD) baseline, admission, and discharge serum creatinine, and mean $( \pm S D)$ duration of anuria and oliguria were observed in patients with non-recovery AKI. The mean $( \pm S D)$ discharge serum creatinine was $5.97( \pm 3.86) \mathrm{mg} / \mathrm{dl}$ which is higher than $3.22( \pm 2.61) \mathrm{mg} / \mathrm{dl}$ in patients with complete recovery. The mean $( \pm S D)$ duration of anuria $4.26 \pm 1.71$ days (range 3-11 days) and oliguria 2.44 \pm 1.10 days (range 2-4days) were also higher in patients with nonrecovery AKI (Table 2 ).

\section{Predictors of renal non-recovery}

Predictors associated with incomplete renal recovery are outlined in Table 3. On univariate logistic regression analysis, non-recovery was significantly associated with age $\geq 60$ years, proteinuria, hypertension, heart failure, AKI stage II, and stage III, and exposure to nephrotoxins. On multivariable logistic regression analysis, patients with proteinuria had more than six times higher risks of renal non-recovery compared to patients without proteinuria (AOR 6.2, Cl 1.25-31.4, p=0.002). Patients with AKI stage III disease had 4.7 times higher risks of renal non-recovery than patients with a less severe stage of AKI (AOR 4.7, Cl 1.37-28.6, p=0.019), and patients with nephrotoxin exposure had more than 5 times increased risks for renal non-recovery than their counterparts (AOR 5.2, Cl 2.1-14.89, $p=0.007$ ).

Table 3: Univariable and multivariable analysis of predictors of non-recovery AKI 


\begin{tabular}{|c|c|c|c|c|c|c|c|}
\hline \multirow[b]{2}{*}{ ariables } & \multirow[b]{2}{*}{ Category } & \multicolumn{2}{|c|}{ Outcome } & \multirow[b]{2}{*}{ OR $(95 \% C I)$} & \multirow[b]{2}{*}{$\begin{array}{l}\text { P- } \\
\text { value }\end{array}$} & \multirow[b]{2}{*}{ AOR (95\%CI) } & \multirow[b]{2}{*}{$\begin{array}{l}P- \\
\text { value }\end{array}$} \\
\hline & & Recovery & $\begin{array}{l}\text { Non- } \\
\text { recovery }\end{array}$ & & & & \\
\hline & & 115 & 54 & & & & \\
\hline \multirow[t]{2}{*}{$\overline{y e}$ in years } & $<60$ & 92 & 35 & Ref & & & \\
\hline & $\geq 60$ & 23 & 19 & $2.1(1.05,4.46)$ & 0.035 & $2.1(0.49,9.13)$ & 0.315 \\
\hline \multirow[t]{2}{*}{ oteinuria } & Absent & 30 & 8 & ref & & & \\
\hline & Present & 14 & 12 & $3.2(1.22,11.4)$ & 0.020 & $6.2(1.25,31.4)$ & $0.002 *$ \\
\hline \multirow[t]{2}{*}{ ypertension } & No & 73 & 21 & Ref & & & \\
\hline & Yes & 42 & 33 & $2.7(1.4,5.31)$ & 0.003 & $5.6(0.84,37.69)$ & 0.074 \\
\hline \multirow[t]{2}{*}{$\overline{\text { eart failure }}$} & No & 71 & 23 & Ref & & & \\
\hline & Yes & 44 & 31 & $2.17(1.12,4.1)$ & 0.021 & $3.7(0.69,19.7)$ & 0.124 \\
\hline \multirow[t]{3}{*}{ age of AKI } & Stage 1 & 61 & 12 & Ref & & & \\
\hline & Stage 2 & 29 & 11 & $3.2(1.36,7.86)$ & 0.008 & $3.1(0.59,15.2)$ & 0.182 \\
\hline & Stage 3 & 25 & 31 & $6.3(2.79,14.2)$ & 0.000 & $4.7(1.37,28.6)$ & $0.019 *$ \\
\hline \multirow[t]{2}{*}{ ephrotoxins } & No & 100 & 37 & Ref & & & \\
\hline & Yes & 15 & 17 & $3(1.39,6.75)$ & 0.005 & $5.2(2.1,14.89)$ & $0.007^{*}$ \\
\hline
\end{tabular}

\section{Ref $=$ reference,$*=$ stastically significant}

Figure 2 shows the cumulative rate of renal recovery by the nephrotoxin exposure status of patients. Patients with nephrotoxic drug exposure had a low rate of renal recovery.

\section{Discussion}

Recovery from acute kidney injury (AKI) in hospitalized patients is variable and persistent impairment of renal function at discharge has been associated with increased mortality, resource utilization, progression to CKD, ESRD, and cardiovascular events. Even small changes in kidney function in hospitalized patients are associated with significant changes in short and long-term outcomes $(1,22)$. Therefore, identifying risk factors leading to incomplete recovery after AKI, maximizing recovery, reducing the burden of CKD, and ESKD in the community should be the goal of any AKI prevention and treatment strategies $(20,23)$.

This study, the first in Ethiopia, found a high prevalence (32\%) of non-recovery AKI at hospital discharge. The degree of non-recovery was higher than findings from other studies, $15.2 \%$ in Cameroon(24), and $20.2 \%$ in South Africa(25). The high prevalence of non-recovery observed in this study could be due to the variation 
with these studies in criteria used for renal recovery (dialysis independent vs return to baseline Scr), and difference in point in time of evaluation of recovery (at hospital discharge vs post-discharge). Studies defining recovery as independent from dialysis show higher rates of recovery than those defining recovery from $\mathrm{AKI}$ as a return to baseline serum creatinine (26). The rate of non-recovery in our study was lower than the results reported from previous studies, $47.3 \%$ in southwest Nigeria(27), $52.8 \%$ in Malawi(28), $60.7 \%$ in Cleveland, Ohio(29), and 61\% in South Korea(30). The variation could be due to differences in sample size, length of follow-up, study design, study setting, patient population (surgical, medical, or mixed), and the inclusion/exclusion of patients with CKD. In addition, since our study is limited only to survivors at discharge, the exclusion of patients who died in the hospital may contribute to the low prevalence of nonrecovery in this study. However, due to the absence of a uniform definition of renal recovery and the difference in the timing of assessment of recovery, the rate of renal non-recovery is different in studies published in the literature. Therefore, it is difficult to compare findings directly across studies $(31,21)$.

Patients discharged with non-recovery AKI had a more severe stage of the disease and a higher mean discharge creatinine value, and mean duration of anuria and oliguria. Likewise, previous studies revealed that a more severe stage of $\mathrm{AKI}$, a higher mean discharge creatinine, and a mean duration of anuria are common in patients with incomplete recovery $(23,28,32,33)$. Interestingly, the severity of AKI was significantly associated with an increased likelihood of non-renal recovery. This is consistent with previous studies that demonstrated a significant association between the severity of AKI and incomplete recovery $(19,29,30,34)$. Furthermore, declined renal function at hospital discharge and severity of AKI are found to be associated with the progression of AKI to CKD and mortality. Therefore, physicians should identify patients with a more severe stage of the disease and manage accordingly to enhance recovery and prevent these adverse outcomes. It is recommended that the intensity of therapeutic and preventive measures should be performed based on the severity of AKI $(1,35)$.

Many studies found an association between exposure to nephrotoxic drugs and the risk of non-renal recovery after AKI. Prescription of nephrotoxic drugs is usually evaluated semi-quantitatively and thus associated with subsequent AKI and CKD, and worsening of lower severity of disease, morbidity, and mortality $(36,37,38)$. This study found that the use of nephrotoxic drugs was associated with a significantly higher chance of non-renal recovery at discharge. The study highlights the need to minimize patients' exposure to nephrotoxic drugs to avoid persistent injury to the kidney, improve renal recovery and prevent subsequent poor short and long-term outcomes AKI. Measures taken to prevent AKI and protect kidney function, such as avoiding nephrotoxins and drug use monitoring can prevent persistent acute kidney injury(19).

One of the main findings of this study found a significant association between proteinuria with non-recovery AKI. As reported in previous studies preadmission proteinuria before an episode of AKI and in-hospital positive urine dipstick test are independent predictors of non-recovery at discharge $(21,32,39)$. Therefore, close monitoring of proteinuria during the period of hospitalization may help to identify patients with persistent AKI and subsequent progressive kidney disease and initiate specific interventions to improve recovery. 
The recovery of kidney function following AKI is shown to be an important determinant of morbidity and mortality. Even after distinct recovery, AKI is shown to be associated with long-term risk for CKD, even for less severe forms. Patients with one episode of mild AKI have significantly lower long-term survival rates than patients with no AKI. As a result, close medical follow-up of these patients is warranted $(22,40,41)$. However, due to the lack of routine renal function tests in many hospitals in the country and periodic follow-up of patients post-discharge (42), the long-term outcomes include mortality, CKD, ESRD, and other adverse outcomes of AKI in our settings are not known.

Our study has some limitations. Firstly, this was a single-center study and exclude patients with underlying CKD. Secondly, urine output assessment was not done for some patients. Moreover, there was no monitoring of the patients after discharge. Therefore, the outcomes of AKI after discharge are not known. Despite these limitations, this is the first prospective observational study of adult medical admissions, which shed some light on the clinical features and recovery status of patients after AKI in resource-limited settings.

\section{Conclusion}

Our study found that most of the patients had AKI on admission and one-third had a higher stage of AKI. A higher proportion of patients were discharged with non-recovery AKI. Renal non-recovery was significantly associated with the severity of AKI, nephrotoxic drug use, and proteinuria. Efforts made to identify the clinical and medication use related factors with close monitoring of renal function tests, urinalysis, and careful drug use monitoring may help to identify patients with a poor renal prognosis, initiate specific interventions, and improve renal recovery at hospital discharge.

\section{Abbreviations}

ACEls; Angiotensin-converting enzyme inhibitor(s), AKI Acute kidney injury, BUN; Blood urea nitrogen, CKD; Chronic kidney disease, ESRD; End-stage renal disease, ICU; Intensive care unit, JMC; Jimma Medical Center, KDIGO; Kidney Disease Improving Global Outcomes, NSAIDs; Non-steroidal anti-inflammatory drugs, RRT; Renal replacement therapy, Scr; Serum creatinine, UOP; Urine output.

\section{References}

1. KDIGO. Clinical Practice Guideline for Acute Kidney Injury. Off J Int Soc Nephrol. 2012;2(1).

2. Wang H. E, Muntner P, Chertow GM, et al. Acute Kidney Injury and Mortality in Hospitalized Patients. Am J Nephrol [Internet]. 2012;35:349-55. Available from: doi: 10.1159/000337487

3. Susantitaphong P, Cruz DN, Cerda J, et al. World Incidence of AKI: A Meta-Analysis. Clin J Am Soc Nephrol [Internet]. 2013;8:1482-93. Available from: doi: 10.2215/CJN.00710113

4. Mehta RL, Cerdá J, Burdmann EA, et al. International Society of Nephrology's Oby25 initiative for acute kidney injury (zero preventable deaths by 2025): a human rights case for nephrology. Lancet. 2015;385:2616-43.

5. Teo S.H, Lee K-G, Koniman R, et al. A prospective study of clinical characteristics and outcomes of acute kidney injury in a tertiary care Centre. BMC Nephrol [Internet]. 2019;20(282):1-8. Available from: 
https://doi.org/10.1186/s12882-019-1466-z

6. Srisawat N, Sileanu FE, Murugan R, et al. Variation in Risk and Mortality of Acute Kidney Injury in Critically III Patients: A Multicenter Study. Am J Nephrol [Internet]. 2015;41:81-8. Available from: doi: $10.1159 / 000371748$

7. Chertow GM, Burdick E, Honour S, et al. Acute Kidney Injury, Mortality, Length of Stay, and Costs in Hospitalized Patients. J Am Soc Nephrol. 2005;16:3365-70.

8. De Corte W, Dhondt A, Vanholder R, et al. Long-term outcome in ICU patients with acute kidney injury treated with renal replacement therapy: a prospective cohort study. Crit Care [Internet]. 2016;20(256):113. Available from: http://dx.doi.org/10.1186/s13054-016-1409-z

9. Liborio AB, Leite TT, Neves FMO, et al. AKI Complications in Critically III Patients: Association with Mortality Rates and RRT. Clin J Am Soc Nephrol [Internet]. 2015;10:21-8. Available from: doi: 10.2215/CJN.04750514

10. James MT, Bhatt M, Pannu N, et al. Long-term outcomes of acute kidney injury and strategies for improved care. Nat Rev Nephrol [Internet]. 2020;1-13. Available from:

http://dx.doi.org/10.1038/s41581-019-0247-z

11. Szczech LA, Granger CB, Dasta JF, et al. Acute Kidney Injury and Cardiovascular Outcomes in Acute Severe Hypertension. Circulation [Internet]. 2010;121:2183-91. Available from: doi: 10.1161/CIRCULATIONAHA.109.896597

12. Godin M, Macedo E, Mehta RL. Clinical Determinants of Renal Recovery. Nephron Clin Pr [Internet]. 2014;127:25-9. Available from: doi: 10.1159/000363707

13. Srisawat N, Murugan R, Wen X, et al. Recovery from acute kidney injury: determinants and predictors. Contrib Nephrol [Internet]. 2010;165:284-91. Available from: https://doi.org/10.1159/000313768

14. Abebe A, Kumela K, Belay M, et al. Mortality and predictors of acute kidney injury in adults: a hospital based prospective observational study. Sci Rep [Internet]. 2021;11(15672):1-8. Available from: https://doi.org/10.1038/s41598-021-94946-3

15. Siew ED, Matheny ME. Choice of Reference Serum Creatinine in Defining Acute Kidney Injury. Nephron Clin Pract [Internet]. 2015;131:107-12. Available from: doi: 10.1159/000439144

16. Thongprayoon C, Cheungpasitporn W, Kittanamongkolchai W, et al. Optimum methodology for estimating baseline serum creatinine for the acute kidney injury classification. Asian Pacific Soc Nephrol. 2015;20:881-6.

17. Siew E. D, Kizler T.A, Matheny ME, et al. Estimating Baseline Kidney Function in Hospitalized Patients with Impaired Kidney Function. Clin J Am Soc Nephrol [Internet]. 2012;7:712-9. Available from: doi: 10.2215/CJN.10821011

18. Ronco, C, Ferrari, F, Ricci Z. Recovery after Acute Kidney Injury: A New Prognostic Dimension of the Syndrome. Amj Resp crit care. 2017;195(6):711-4.

19. Forni L.G, Darmon M, Ostermann M, et al. Renal recovery after acute kidney injury. Intensive Care Med [Internet]. 2017;43(6):855-66. Available from: https://doi.org/10.1007/s00134-017-4809-x

20. Kellum JA, Sileanu FE, Bihorac A, et al. Recovery after Acute Kidney Injury. Ame J Respi Criti Care Medi [Internet]. 2017;195(6):784-91. Available from: doi: 10.1164/rccm.201604-07990C 
21. Chawla LS, Bellomo R, Bihorac A, et al. Acute kidney disease and renal recovery: consensus report of the Acute Disease Quality Initiative (ADQI) 16 Workgroup. Nat rev [Internet]. 2017;43(241):1-17. Available from: doi:10.1038/nrneph.2017.2

22. Linder A, Fjell C, Levin A, et al. Small Acute Increases in Serum Creatinine Are Associated with Decreased Long-Term Survival in the Critically III. Am J Respir Crit Care Med [Internet]. 2014;189(9):1075-81. Available from: doi: 10.1164/rccm.201311-20970C

23. Jung $\mathrm{H}-\mathrm{Y}$, Lee J-H, Park Y-J, et al. Duration of anuria predicts recovery of renal function after acute kidney injury requiring continuous renal replacement therapy. Korean J Intern Med [Internet]. 2016;31:930-7. Available from: http://dx.doi.org/10.3904/kjim.2014.290

24. HALLE MPE, Chipekam NM, Beyiha G, et al. Incidence, characteristics and prognosis of acute kidney injury in Cameroon: a prospective study at the Douala General Hospital. Ren Fail [Internet]. 2018;40(1):30-7. Available from: https://doi.org/10.1080/0886022X.2017.1419970

25. Dlamini TAL, Heering PJ, Chivese T, et al. A prospective study of the demographics, management and outcome of patients with acute kidney injury in Cape Town, South Africa. PLoS One [Internet]. 2017;12(6):1-12. Available from: doi.org/10.1371/journal.pone.0177460

26. Schiff H. Renal recovery from acute tubular necrosis requiring renal replacement therapy: a prospective study in critically ill patients. Nephrol Dial Transpl [Internet]. 2006;21:1248-52. Available from: doi:10.1093/ndt/gfk069

27. Oluseyi A, Ayodeji A, Ayodeji F. Aetiologies and Short-term Outcomes of Acute Kidney Injury in a Tertiary Centre in Southwest Nigeria. Ethiop J Heal Sci [Internet]. 2016;26(1):37-44. Available from: doi:http://dx.doi.org/10.4314/ejhs.v26i1.8

28. Evans RDR, Hemmilä U, Craik A, et al. Incidence, aetiology and outcome of community-acquired acute kidney injury in medical admissions in Malawi. BMC Nephrol [Internet]. 2017;18(21):1-9. Available from: DOI 10.1186/s12882-017-0446-4

29. Panitchote $A$, Mehkri $O$, Hastings $A$, et al. Clinical predictors of renal non-recovery in acute respiratory distress syndrome. BMC Nephrol [Internet]. 2019;20(255):1-10. Available from: https://doi.org/10.1186/s12882-019-1439-2

30. Park YS, Choi YH, Oh JH, et al. Recovery from acute kidney injury as a potent predictor of survival and good neurological outcome at discharge after out-of-hospital cardiac arrest. Crit Care [Internet]. 2019;23(256):1-11. Available from: https://doi.org/10.1186/s13054-019-2535-1

31. Gaião SM, Gomes AA, Paiva JAOdC. Prognostics factors for mortality and renal recovery in critically ill patients with acute kidney injury and renal replacement therapy. Rev Bras Ter Intensiva [Internet]. 2016;28(1):70-7. Available from: doi: 10.5935/0103-507X.20160015

32. Zhang N-H, Cheng Y-C, Luo R, et al. Recovery of new-onset kidney disease in COVID-19 patients discharged from hospital. BMC Infect Dis [Internet]. 2021;21(397):1-9. Available from: https://doi.org/10.1186/s12879-021-06105-8

33. Xu J, Xu X, Shen B, et al. Evaluation of five different renal recovery definitions for estimation of longterm outcomes of cardiac surgery associated acute kidney injury. BMC Nephrol [Internet]. 2019;20(427):1-8. Available from: https://doi.org/10.1186/s12882-019-1613-6 
34. Okyere P, Okyere I, Ndanu TA, et al. Factors associated with acute kidney injury recovery in a tertiary hospital in Ghana: a prospective study. Pan Afr Med J [Internet]. 2019;33(236):1-11. Available from: doi:10.11604/pamj.2019.33.236.15507

35. Ponce $L$, Balbi AL, Rocha EPd, et al. The long-term outcome after acute kidney injury: a narrative review. J Bras Nefrol [Internet]. 2015;37(1):115-20. Available from: doi: 10.5935/0101-2800.20150016

36. Pazhayattil G, Shirali A. Drug-induced impairment of renal function. Int J Nephrol Renovasc Dis [Internet]. 2014;7:457-68. Available from: http://dx.doi.org/10.2147/IJNRD.S39747

37. Ehrmann S, Helms J, Joret A, et al. Nephrotoxic drug burden among 1001 critically ill patients: impact on acute kidney injury. Ann Intensive Care [Internet]. 2019;9(106):1-9. Available from: https://doi.org/10.1186/s13613-019-0580-1

38. Sari A. Nephrotoxic Effects of Drugs:Poisoning in the Modern World - New Tricks for an Old Dog? In: IntechOpen [Internet]. 2019. Available from: doi: http://dx.doi.org/10.5772/intechopen.83644

39. https://doi.org/10.1016/j.kint.2017.10.017

40. Heung M, Steffick DE, Zivin K, et al. Acute Kidney Injury Recovery Pattern and Subsequent Risk of CKD: An Analysis of Veterans Health Administration Data. Am J Kidney Dis [Internet]. 2016;67(5):742-52. Available from: http://dx.doi.org/10.1053/j.ajkd.2015.10.019

41. Bagshaw SM. Short- and long-term survival after acute kidney injury. Nephrol Dial Transpl [Internet]. 2008;23:2126-8. Available from: doi: 10.1093/ndt/gfn300

42. Riley S, DIRO E, BATCHELOR P, et al. Renal impairment among acute hospital admissions in a rural Ethiopian hospital: nephrology [Internet]. 2013;18:92-6. Available from: doi:10.1111/nep.12002

\section{Declarations}

\section{Ethical approval and consent to participate}

The study meets the ethical standards outlined in national and international guidelines and is conducted in accordance with the principles of the Declaration of Helsinki. The study was authorized by the ethical committee of Jimma University. Written informed consent was secured from all participants and collected data was kept confidential.

\section{Consent for Publication}

"Not applicable"

\section{Availability of data and materials}

All data used for this study will be made available by the corresponding author upon reasonable request.

\section{Competing interests}

The authors declare that they have no competing interests. 


\section{Funding}

"Not applicable"

\section{Author Contributions}

A.A., K.K., and M.B. contributed to the conception and design of the study and discussion and interpretation of the results. A.B., Y.W., and E.A. contributed to the data collection, analysis, and drafting of the manuscript. All authors revised and approved the final manuscript.

\section{Acknowledgments}

The authors are grateful to Jimma University, the staffs of the hospital, and thank the patients for their dedication that enables the successful completion of this study.

\section{Figures}

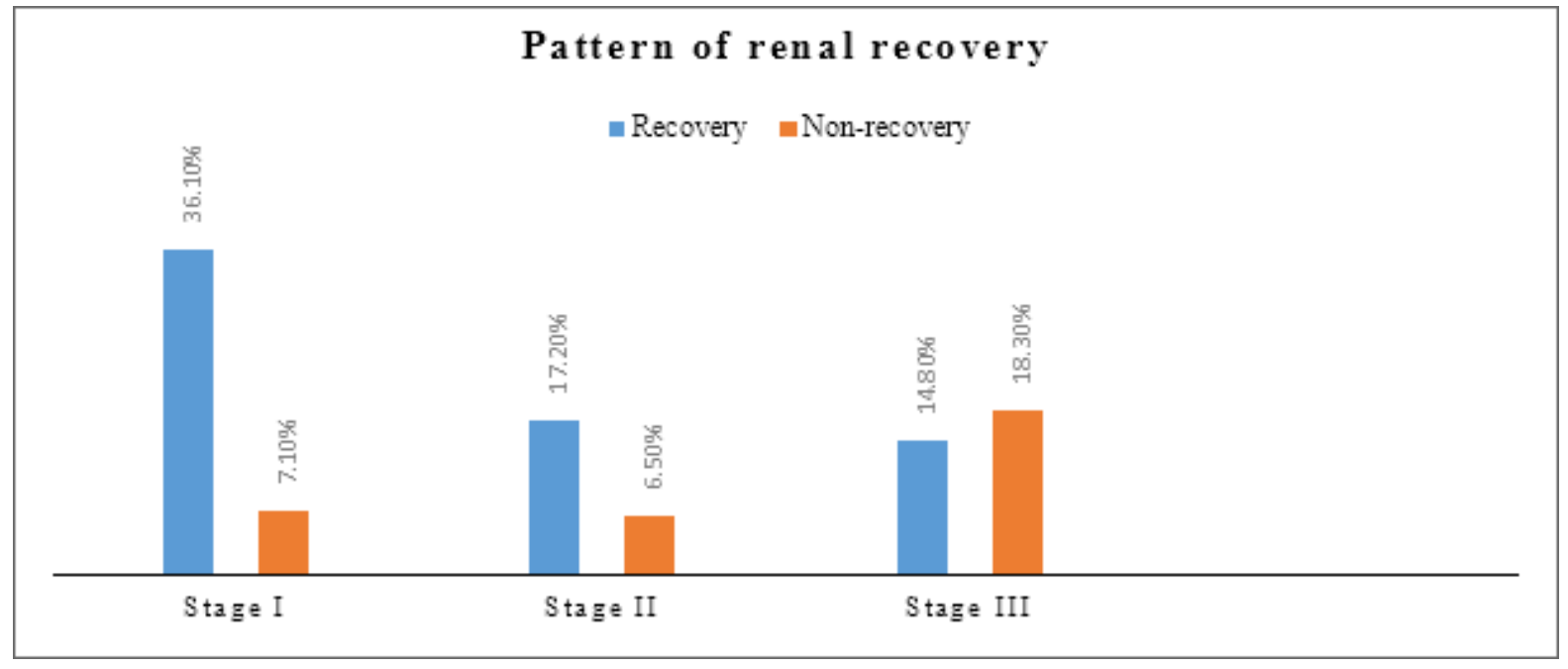

Figure 1

Pattern of renal recovery by stage of acute kidney injury 


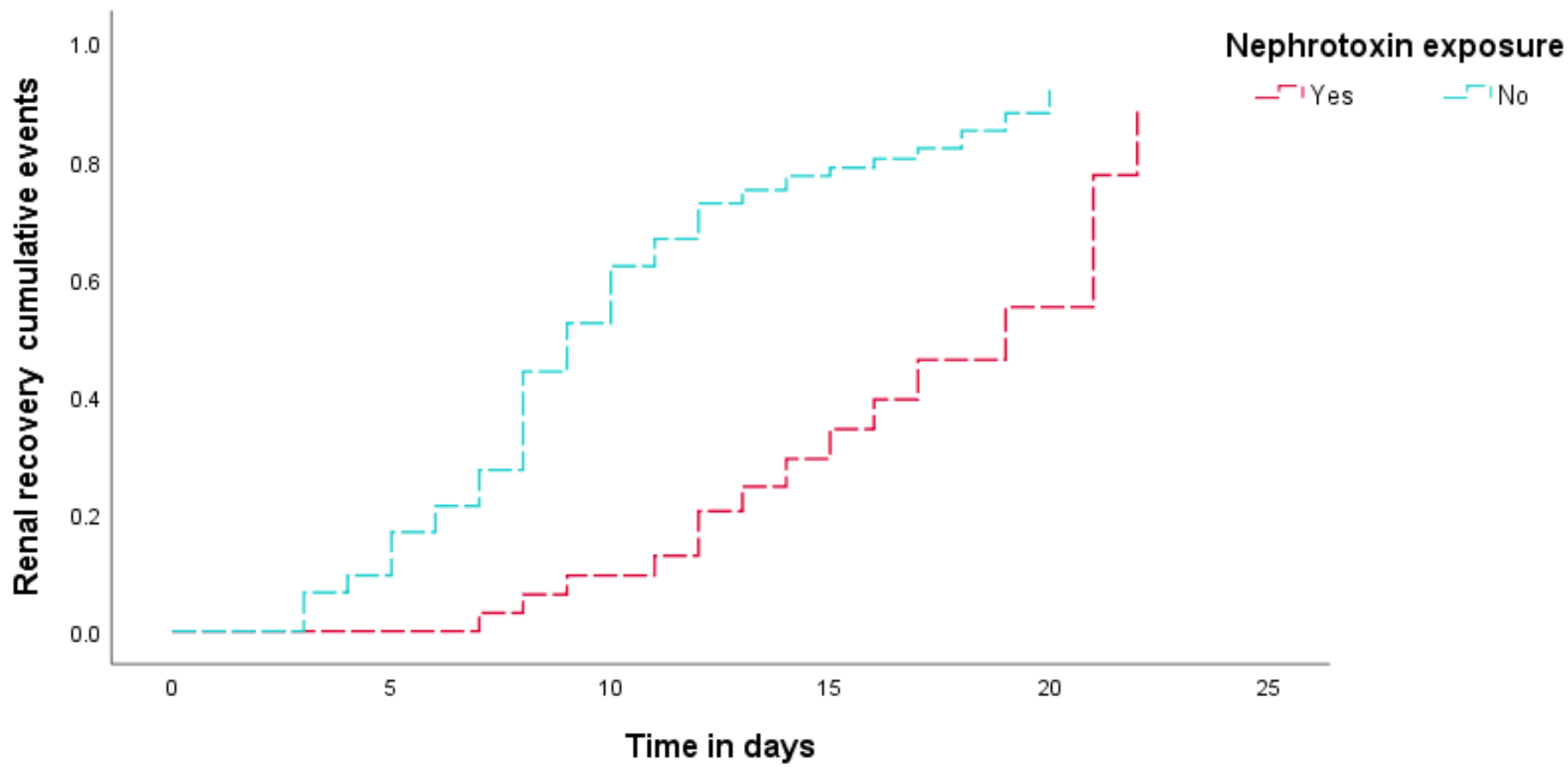

Figure 2

Kaplan-Meier curve of the cumulative renal recovery rate by nephrotoxin exposure 